\title{
Leaf Area Estimation Model for Small Fruits from Linear Measurements
}

\author{
Carlo Fallovo ${ }^{1}$, Valerio Cristofori, Emilio Mendoza de-Gyves, Carlos \\ Mario Rivera, Roberto Rea, and Simone Fanasca \\ Dipartimento de Produzione Vegetale, Università della Tuscia, Via S. \\ Camillo de Lellis, 01100 Viterbo, Italy
}

\section{Cristina Bignami}

Dipartimento de Science Agrarie e degli Alimenti, Università degli Studi di Modena e Reggio Emilia, Via Amendola 2, pad. Besta, 42100 Reggio Emila, Italy

\section{Youssef Sassine and Youssef Rouphael \\ Department of Crop Production, Faculty of Agricultural and Veterinary Sciences, Lebanese University, Dekwaneh-Al Maten, Lebanon}

Additional index words. blackberry, gooseberry, highbush blueberry, individual leaf area, nondestructive methods, raspberry, redcurrant

\begin{abstract}
Accurate and nondestructive methods to determine individual leaf areas of plants are a useful tool in physiological and agronomic research. Determining the individual leaf area (LA) of small fruit like raspberry (Rubus idaeus L.), redcurrant (Ribes rubrum L.), blackberry (Rubus fruticosus L.), gooseberry (Ribes grossularia L.), and highbush blueberry (Vaccinium corymbosum $\mathrm{L}$.) involves measurements of leaf parameters such as length $(\mathrm{L})$ and width $(\mathrm{W})$ or some combinations of these parameters. A 2-year investigation was carried out during 2006 (on seven raspberry, seven redcurrant, six blackberry, five gooseberry, and two highbush blueberry cultivars) and 2007 (on one cultivar per species) under open field conditions to test whether a model could be developed to estimate LA of small fruits across cultivars. Regression analysis of LA versus $L$ and $W$ revealed several models that could be used for estimating the area of individual small fruit leaves. A linear model having $L W$ as the independent variable provided the most accurate estimate (highest $R^{2}$, smallest mean square error, and the smallest predicted residual error sum of squares) of $L A$ in all small fruit berries. Validation of the model having $L W$ of leaves measured in the 2007 experiment coming from other cultivars of small fruit berries showed that the correlation between calculated and measured small fruit berries LAs was very high. Therefore, these models can estimate accurately and in large quantities the LA of small fruit plants in many experimental comparisons without the use of any expensive instruments.
\end{abstract}

Plant leaf area is an important determinant of light interception and consequently of transpiration, photosynthesis, and plant productivity (Goudriaan and Van Laar, 1994). Plant physiologists and agronomists have demonstrated the importance of this parameter in estimating crop growth, development rate, yield potential, radiation use efficiency, and water and nutrient use (Williams and Martinson, 2003).

Leaf area can be measured by destructive or nondestructive measurements. Many methods have been devised to facilitate the measurement of leaf area. However, these methods, including those of tracing, blueprinting, photographing, or using a conventional planimeter, require the excision of leaves from the plants. It is therefore not possible to make successive measurements of

Received for publication 6 Aug. 2008. Accepted for publication 3 Sept. 2008.

${ }^{1}$ To whom reprint requests should be addressed; e-mail fallovo@unitus.it the same leaf. Plant canopy is also damaged, which might cause problems to other measurements or experiments. Leaf area can be measured quickly, accurately, and nondestructively using a portable scanning planimeter (Daughtry, 1990), but it is suitable only for small plants with few leaves (Nyakwende et al., 1997). An alternative method to measure leaf area is to use image analysis with image measurement and analysis software. The capture of image by digital camera is rapid, and the analysis using proper software is accurate (Bignami and Rossini, 1996), but the processing is time-consuming and the facilities are generally expensive. Therefore, an inexpensive, rapid, reliable, and nondestructive method for measuring leaf area is required by the agronomists. If the mathematical relationships between leaf area and one or more dimensions of the leaf (length and width) could be clarified, a method using just linear measurements to estimate leaf area would be more advantageous than many of the methods mentioned here (Beerling and Fry, 1990). Various combinations of meas- urements and various models relating length and width to area have been developed for many horticultural crops such as cucumber (Cho et al., 2007), pepper (De Swart et al., 2004), grape (Williams and Martinson, 2003), strawberry (Demirsoy et al., 2005), muskmelon (Panta and NeSmith, 1995), faba bean (Peksen, 2007), zucchini squash (Rouphael et al., 2006), tomato (Schwarz and Kläring, 2001), broccoli (Stoppani et al., 2003), radish (Salerno et al., 2005), and for fruit trees (Cristofori et al., 2007; Demirsoy et al., 2004; Serdar and Demirsoy, 2006), whereas information on the estimation of several small fruit leaf areas such as raspberry (Rubus idaeus L.), redcurrant (Ribes rubrum L.), blackberry (Rubus fruticosus L.), gooseberry (Ribes grossularia L.), and highbush blueberry (Vaccinium corymbosum L.) is still lacking despite some studies on raspberry and redcurrant (Uzun and Çelik, 1999).

The accuracy of the predictions is dependent on the variation of leaf shape between cultivars. Because leaf shape (length:width ratio) may vary among different genetic materials (Stoppani et al., 2003), we needed a good model of nondestructive leaf area estimation to use in physiological study of small fruit plants independently of the genetic materials.

Therefore, the aims of this study were: 1) to develop a model for leaf area prediction from linear measurements of leaf length and width in different small fruit that was able to accommodate the effect of changes in leaf shape between cultivars and which could be used for raspberry, redcurrant, blackberry, gooseberry, and highbush blueberry plants of all accessions without recalibration; and 2) to assess the robustness of the selected models on an independent set of data from other cultivar.

\section{Materials and Methods}

Data collection. Eight raspberry (Rubus idaeus L.), eight redcurrant (Ribes rubrum L.), seven blackberry (Rubus fruticosus L.), six gooseberry (Ribes grossularia L.), and three highbush blueberry (Vaccinium corymbosum L.) cultivars collected from experimental and private farms were used to develop the leaf area prediction models. Wide varieties of fully expanded leaf samples were used. Leaves varied in size from large to small for each cultivar and were selected randomly from different levels of the canopy during the summer growing season in 2006 and 2007. The age of the shrubs varied between 3 and 5 years.

Model building. A total of 701 raspberry, 758 redcurrant, 600 blackberry, 500 gooseberry, and 201 highbush blueberry leaves $(\approx 100$ leaves per cultivar) were measured for leaf area (LA), length (L), and width (W) in the preliminary calibration experiment coming from 27 cultivars: Meeker, Tulameen, Zeva, Heritage, Willamette, Malling Exploit, and Malling Promise for raspberry; Rosetta, Primus, Rolan, Red Poll, Jonkheer, Rood Neus, and Augustus for redcurrant; Cheyenne, 
Loch Ness, Triple Crown, Rondom, Waldo, and Smoothstem for blackberry; Green Finch, Rokula, Pax, Whinham's industry, and Hinninmaki Gul for gooseberry; and Blue Crop and Duke for highbush blueberry grown under field conditions at the experimental farms of Frosinone (Latium region, central Italy) and Caserta (Campania region, South Italy) and private farms of Caprarola, Ronciglione, and Vetralla (Latium region, central Italy). These cultivars were selected as a representative sampling of many small fruit berries cultivated in the warm areas of China, Korea, Japan, the United States, and for some of them, introduced in the Mediterranean region (Spain, Italy, Greece, and France) (Bounous et al., 2004). Raspberry, redcurrant, blackberry, gooseberry, and highbush blueberry shrubs were spaced $0.65 \times$ $2.50 \mathrm{~m}, 1.25 \times 2.50 \mathrm{~m}, 2.00 \times 2.50 \mathrm{~m}, 1.25 \times$ $2.50 \mathrm{~m}$, and $0.50 \times 2.50 \mathrm{~m}$, respectively, giving a plant density of $6150,3200,2000,3200$, and 8000 plants/ha, respectively.

Immediately after cutting, leaves were placed in plastic bags and were transported on ice to the laboratory. Leaf length was measured from the lamina tip to the point of intersection of the lamina and the petiole, along the midrib of the lamina, whereas leaf width was measured from end-to-end between the widest lobes of the lamina perpendicular to the lamina midrib. Values of $\mathrm{L}$ $(\mathrm{cm})$ and $\mathrm{W}(\mathrm{cm})$ were recorded to the nearest $0.1 \mathrm{~cm}$. The area of each leaf (LA) was measured using an area meter (LI-3100; LICOR, Lincoln, NE) calibrated to $0.01 \mathrm{~cm}^{2}$.

The relationships were evaluated by fitting regression models with the linear regression procedure of SPSS (SPSS Inc., Chicago, IL) and the stepwise elimination option as reported by Miranda and Royo (2003a). The internal validity of the models was tested by coefficient of determination $\left(R^{2}\right)$, mean square error (MSE), and predicted residual error sum of squares (PRESS). Residuals were analyzed to determine the presence of outliers and nonconstant error variance. Outlier is defined as:

$$
\text { Outlier }=\left\{\begin{array}{l}
0 \text { if }\left|\mathrm{r}_{\mathrm{i}}\right| \leq \mathrm{k} \sigma \\
1 \text { otherwise }
\end{array}\right.
$$

where, by default, $\mathrm{k}=3$ and scale $\sigma$ is computed as corrected median of the absolute residuals (Cankaya et al., 2006; Peksen, 2007).

Leaf area was the dependent variable and the independent variables were $\mathrm{L}, \mathrm{W}, \mathrm{L}^{2}, \mathrm{~W}^{2}$, and the product $\mathrm{L} \times \mathrm{W}$. MSE, PRESS, error sum of squares (SSE), and the values of the coefficients $(b)$ and constants $(a)$ were also reported (Table 1); and the final model was selected based on the combination of the highest $R^{2}$, the lowest MSE, the lowest PRESS, and when the PRESS values are reasonably close to SSE. Individualized models for each cultivar of the different small fruit berries have been built. In all, individual models involved alone LW parameter, which was the main parameter explaining a big part

Table 1. Fitted coefficient $(b)$ and constant ( $a$ ) values of the models used to estimate the small fruit berries leaf area (LA) of single leaves from length (L) and width (W) measurements.

\begin{tabular}{|c|c|c|c|c|c|c|c|}
\hline \multirow[b]{2}{*}{ Model no. } & \multirow{2}{*}{$\begin{array}{c}\text { Form of model } \\
\text { tested }\end{array}$} & \multicolumn{2}{|c|}{$\begin{array}{l}\text { Fitted coefficient } \\
\text { and constant }\end{array}$} & \multirow[b]{2}{*}{$R^{2 z}$} & \multirow[b]{2}{*}{$\mathrm{MSE}^{\mathrm{z}}$} & \multirow[b]{2}{*}{ PRESS $^{z}$} & \multirow[b]{2}{*}{$\mathrm{SSE}^{\mathrm{z}}$} \\
\hline & & 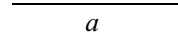 & $b$ & & & & \\
\hline & & \multicolumn{6}{|c|}{ Raspberry (Rubus idaeus L.) } \\
\hline 1 & $\mathrm{LA}=a+b \mathrm{~L}$ & $-26.26(1.02)^{\mathrm{y}}$ & $7.52(0.14)$ & 0.851 & 58.59 & 35,278 & 34,980 \\
\hline 2 & $\mathrm{LA}=a+b \mathrm{~W}$ & $-17.73(0.50)$ & $9.05(0.10)$ & 0.936 & 24.95 & 15,067 & 14,897 \\
\hline 3 & $\mathrm{LA}=a+b \mathrm{LW}$ & $0.03(0.19)$ & $0.71(0.00)$ & 0.982 & 7.76 & 4,677 & 4,633 \\
\hline 4 & $\mathrm{LA}=a+b \mathrm{~L}^{2}$ & $-1.04(0.53)$ & $0.52(0.01)$ & 0.868 & 50.42 & 30,380 & 30,104 \\
\hline \multirow[t]{2}{*}{5} & $\mathrm{LA}=a+b \mathrm{~W}^{2}$ & $5.70(0.30)$ & $0.78(0.01)$ & 0.945 & 20.28 & 13,401 & 13,303 \\
\hline & & \multicolumn{6}{|c|}{ Redcurrant (Ribes rubrum L.) } \\
\hline 1 & $\mathrm{LA}=a+b \mathrm{~L}$ & $-15.22(0.67)$ & $8.04(0.13)$ & 0.892 & 34.64 & 20,328 & 20,058 \\
\hline 2 & $\mathrm{LA}=a+b \mathrm{~W}$ & $-19.74(0.52)$ & $7.49(0.08)$ & 0.943 & 18.02 & 10,584 & 10,432 \\
\hline 3 & $\mathrm{LA}=a+b \mathrm{LW}$ & $1.72(0.19)$ & $0.69(0.00)$ & 0.980 & 7.15 & 4,183 & 4,139 \\
\hline 4 & $\mathrm{LA}=a+b \mathrm{~L}^{2}$ & $2.89(0.34)$ & $0.77(0.01)$ & 0.930 & 22.94 & 13,442 & 13,280 \\
\hline \multirow[t]{2}{*}{5} & $\mathrm{LA}=a+b \mathrm{~W}^{2}$ & $2.12(0.24)$ & $0.57(0.01)$ & 0.965 & 11.79 & 6,928 & 6,828 \\
\hline & & \multicolumn{6}{|c|}{ Blackberry (Rubus fruticosus L.) } \\
\hline 1 & $\mathrm{LA}=a+b \mathrm{~L}$ & $-15.56(1.01)$ & $6.19(0.15)$ & 0.866 & 46.57 & 27,806 & 27,572 \\
\hline 2 & $\mathrm{LA}=a+b \mathrm{~W}$ & $-15.28(0.69)$ & $8.17(0.13)$ & 0.901 & 25.48 & 15,233 & 15,083 \\
\hline 3 & $\mathrm{LA}=a+b \mathrm{LW}$ & $0.90(0.18)$ & $0.70(0.00)$ & 0.975 & 4.61 & 2,755 & 2,731 \\
\hline 4 & $\mathrm{LA}=a+b \mathrm{~L}^{2}$ & $3.43(0.52)$ & $0.46(0.01)$ & 0.895 & 39.43 & 23,536 & 23,341 \\
\hline \multirow[t]{2}{*}{5} & $\mathrm{LA}=a+b \mathrm{~W}^{2}$ & $4.8(0.37)$ & $0.76(0.01)$ & 0.922 & 21.56 & 14,095 & 13,945 \\
\hline & & \multicolumn{6}{|c|}{ Gooseberry (Ribes grossularia L.) } \\
\hline 1 & $\mathrm{LA}=a+b \mathrm{~L}$ & $-3.64(0.26)$ & $3.86(0.11)$ & 0.855 & 1.02 & 301 & 296 \\
\hline 2 & $\mathrm{LA}=a+b \mathrm{~W}$ & $-4.02(0.19)$ & $3.46(0.07)$ & 0.928 & 0.57 & 167 & 164 \\
\hline 3 & $\mathrm{LA}=a+b \mathrm{LW}$ & $0.58(0.09)$ & $0.72(0.01)$ & 0.974 & 0.37 & 109 & 108 \\
\hline 4 & $\mathrm{LA}=a+b \mathrm{~L}^{2}$ & $0.94(0.13)$ & $0.77(0.02)$ & 0.873 & 0.92 & 271 & 267 \\
\hline \multirow[t]{2}{*}{5} & $\mathrm{LA}=a+b \mathrm{~W}^{2}$ & $0.86(0.10)$ & $0.58(0.01)$ & 0.939 & 0.51 & 149 & 146 \\
\hline & & \multicolumn{6}{|c|}{ Highbush blueberry (Vaccinium corymbosum L.) } \\
\hline 1 & $\mathrm{LA}=a+b \mathrm{~L}$ & $-11.53(0.88)$ & $4.23(0.15)$ & 0.867 & 3.18 & 540 & 528 \\
\hline 2 & $\mathrm{LA}=a+b \mathrm{~W}$ & $-6.37(0.46)$ & $6.31(0.14)$ & 0.919 & 1.52 & 271 & 263 \\
\hline 3 & $\mathrm{LA}=a+b \mathrm{LW}$ & $0.54(0.13)$ & $0.68(0.01)$ & 0.986 & 0.27 & 47 & 46 \\
\hline 4 & $\mathrm{LA}=a+b \mathrm{~L}^{2}$ & $0.10(0.46)$ & $0.37(0.01)$ & 0.899 & 2.95 & 500 & 489 \\
\hline 5 & $\mathrm{LA}=a+b \mathrm{~W}^{2}$ & $3.06(0.26)$ & $1.01(0.02)$ & 0.942 & 1.59 & 259 & 253 \\
\hline
\end{tabular}

${ }^{\mathrm{z}}$ Coefficient of determination $\left(R^{2}\right)$, mean square errors $\left(\mathrm{MSE}\right.$ in $\left.\mathrm{cm}^{2}\right)$, predicted residual error sum of squares (PRESS), and error sum of squares (SSE) of the various models are also given.

${ }^{{ }^{S}}{ }_{S E S}$ in parentheses; $\mathrm{L}$ and $\mathrm{W}$ were in centimeters.

of total variation for LA. In addition, WilkesShapiro W statistic test result revealed that data pooled from all cultivars showed normal distribution. For this reason, data were pooled and a single relationship calculated to develop the LA prediction model for small fruit berries. Finally, using two measurements (i.e., L and W) introduces potential problems of collinearity, resulting in poor precision in the estimates of the corresponding regression coefficients. For detecting collinearity, the variance inflation factor (VIF) (Marquardt, 1970) and the tolerance values $(\mathrm{T})($ Gill, 1986) were calculated.

$$
\begin{aligned}
\mathrm{VIF} & =\frac{1}{\left(1-r^{2}\right)} \\
\mathrm{T} & =\frac{1}{\mathrm{VIF}}
\end{aligned}
$$

where $r$ is the correlation coefficient. If the VIF value was higher than 10 or if the T value was smaller than 0.10 , then collinearity may have more than a trivial impact on the estimates of the parameters, and consequently one of them should be excluded from the model.

Validation experiment. In addition to validate the developed models of small fruit berries and to increase practical applicability, a validation experiment was conducted in Summer 2007 on leaf samples of 'Autumn
Bliss' (raspberry), 'Rovada' (redcurrant), 'Hull Thornless' (blackberry), 'Careless' (gooseberry), and 'Coville' (highbush blueberry) grown at the Experimental Farm of Tuscia University, central Italy (lat. $42^{\circ} 25^{\prime}$ $\mathrm{N}$, long. $12^{\circ} 08^{\prime} \mathrm{E}$, altitude $310 \mathrm{~m}$ ). These cultivars were selected as the most representative small fruit cultivars cultivated in Italy.

To validate the model, $\approx 150$ leaves of 'Autumn Bliss', 'Rovada', 'Hull Thornless', 'Careless', and 'Coville' actual LA and leaf width and length were determined by the previously described procedures. Two techniques reported by Miranda and Royo (2003a, 2003 b , 2004) were used to validate the models for small fruit berries: 1) the validation data set was used to produce a validation model by re-estimating the model parameters using the Stepwise Regression Option approach to develop the estimation model and the models were compared for consistency; 2) regression parameter estimates from the estimation models were used to predict outcomes for observations in the validation data set and then the mean squared prediction error (MSPR) was calculated and compared with the MSE of the regression fit to the model building data set (Neter et al., 1996). To compare the predicted leaf area (PLA) with the observed leaf area (OLA) for the cultivars of small fruit berries during the 2007 growing season, graphical procedures (Bland and Altman, 1986) were used. Scatterplots of values for the PLA against the OLA are presented (Fig. 1). 

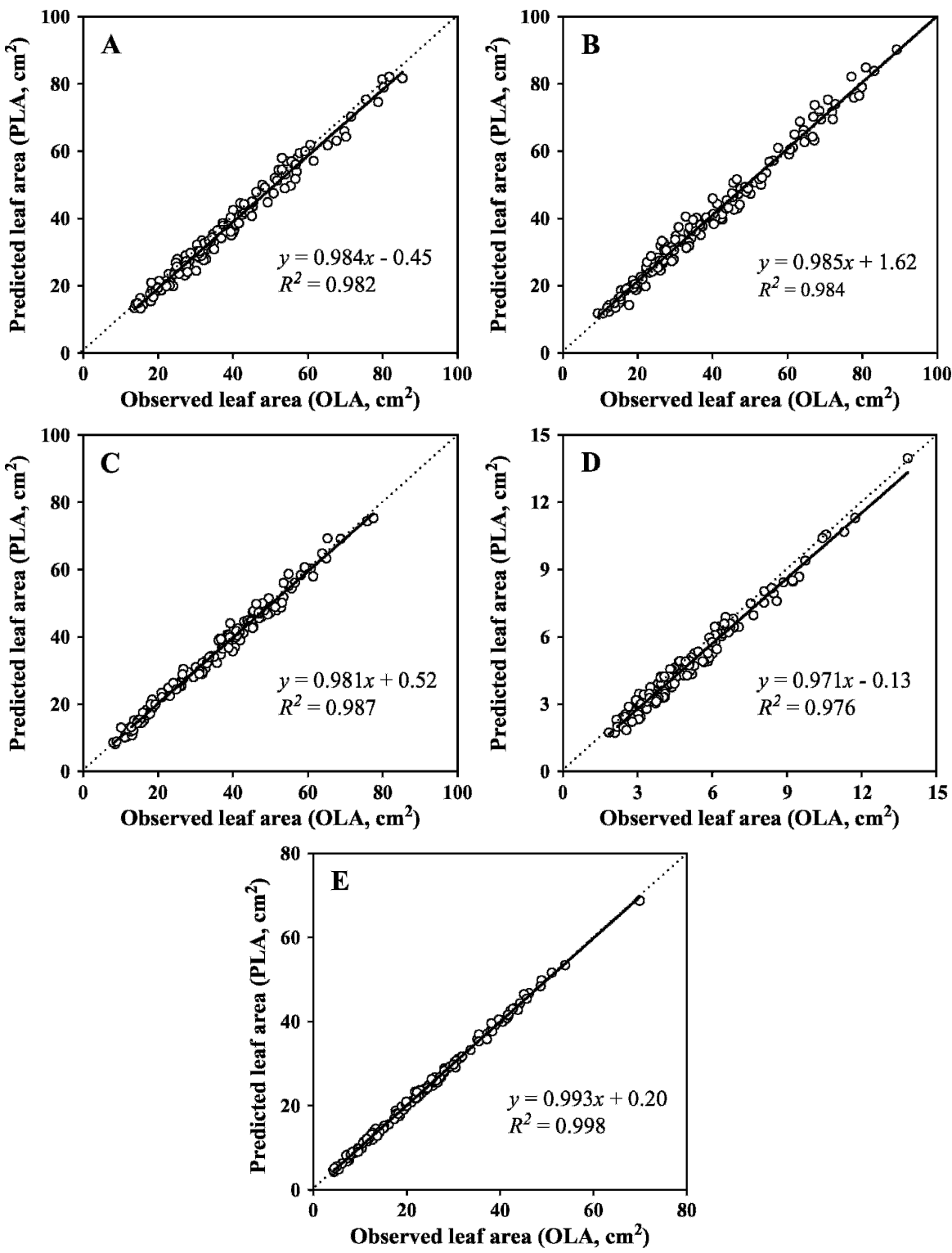

Fig. 1. Plot of predicted leaf area (PLA) using Model 3 versus observed values of single leaf areas (OLA) of 'Autumn Bliss' (raspberry, A), 'Rovada' (redcurrant, B), 'Hull Thornless' (blackberry, C), 'Careless' (gooseberry, D), and 'Coville' (highbush blueberry, E) during 2007 (validation experiment). Solid line represents linear regression lines of Model 3. Dotted lines represent the 1:1 relationship between the predicted and observed values.

The GLM procedure of SPSS (SPSS Inc.) was used to evaluate the linear relationship for OLA and PLA. Values for PLA were subtracted from OLA for the cultivars Autumn Bliss, Rovada, Hull Thornless, Careless, and Coville and differences were plotted against the OLA for each of them. Lack of agreement was evaluated by calculating the relative bias estimated by the mean of the differences (d) and the SD of the differences (Fig. 2). Normality test was carried out to obtain a WilkesShapiro W statistic using the examines procedure of SPSS (Marini, 2001).

\section{Results and Discussion}

As a preliminary step to model calibration, the degree of collinearity among $\mathrm{W}$ and $\mathrm{L}$ was analyzed. The VIF ranged from 1.6 to
2.9 for raspberry, from 3.0 to 8.8 for redcurrant, from 2.6 to 4.2 for blackberry, from 2.8 to 6.0 for gooseberry, and from 2.5 to 4.4 for highbush blueberry. Moreover, $\mathrm{T}$ values ranged from 0.34 to 0.63 for raspberry, from 0.12 to 0.33 for redcurrant, from 0.23 to 0.38 for blackberry, from 0.16 to 0.35 for gooseberry, and from 0.22 to 0.39 for highbush blueberry depending on the cultivar. In all cultivars, VIF was less than 10 and $\mathrm{T}$ was greater than 0.10 , showing that the collinearity between $\mathrm{L}$ and $\mathrm{W}$ can be considered negligible (Gill, 1986) and these variables can be both included in the model.

Model calibration. Regression analysis demonstrated strong relationships $(P<$ 0.001 ) between LA and midvein length $(\mathrm{L})$, maximum leaf width $(\mathrm{W})$, the product of length and width (LW), the square of length
$\left(\mathrm{L}^{2}\right)$, and the square of width $\left(\mathrm{W}^{2}\right)$ (Table 1$)$. This is in agreement with previous studies (Cristofori et al., 2007; Mendoza de Gyves et al., 2007; Peksen, 2007; Rivera et al., 2007; Rouphael et al., 2006, 2007) on nondestructive model development for predicting LA using simple linear measurements. However, suitability of these models varied based on the selection criteria previously described. Except for Model 1, all models produced a coefficient of determination $\left(R^{2}\right)$ greater than 0.85 (Table 1). Based on selection criteria previously described (higher $R^{2}$, lower MSE, lower PRESS, and when the PRESS values were reasonably close to SSE), this study demonstrated that models with a single measurement of L (Models 1 and 4, Table 1) were less acceptable for estimating LA of small fruit berries as a result of their lowest coefficient of determination $\left(R^{2}\right)$, higher MSE, and higher PRESS values. An improvement was possible for single LA estimation when $\mathrm{W}^{2}$ (Model 5) was used as the independent variable (Table 1). To find a model to predict single LA accurately for small fruit berries of all cultivars, the product of $\mathrm{L} \times \mathrm{W}$ was used as the independent variable (Model 3). We preferred this linear model $(\mathrm{LA}=0.03+0.71 \mathrm{LW}$ for raspberry, $\mathrm{LA}=1.72+0.69 \mathrm{LW}$ for redcurrant, $\mathrm{LA}=$ $0.90+0.70 \mathrm{LW}$ for blackberry, $\mathrm{LA}=0.58+$ $0.72 \mathrm{LW}$ for gooseberry, and LA $=0.54+$ $0.68 \mathrm{LW}$ for highbush blueberry) for its accuracy: highest $R^{2}$ (greater than 0.97), smallest MSE, smallest PRESS, and to the reasonably close PRESS value to SSE (Table 1). PRESS criterion and SSE are measures of how well the use of the fitted values for a subset model can predict the observed values of the response value $Y_{i}$. Some evidence of the internal validity of the fitted model is to compare PRESS and SSE (Miranda and Royo, 2003a). PRESS value is always larger than SSE because the regression fit for the $i^{\text {th }}$ case, when this case is deleted in fitting, can never be as good as that when the $i^{\text {th }}$ case is included. In the current study, PRESS value of all small fruit berries was reasonably close to SSE for the LA Model 3 (Table 1) and supports the validity of the fitted regression model and of the MSEs as an indication of the predictive capability of this model (Neter et al., 1996). Based on these considerations, both $\mathrm{L}$ and $\mathrm{W}$ measurements were necessary to estimate small fruit berries' LA accurately.

The shape coefficient (regression coefficient of Model 3) can be described by a shape between an ellipse (0.78) and a triangle (0.5) of the same length and maximum width. Our shape coefficients $(0.71$ for raspberry, 0.69 for redcurrant, 0.70 for blackberry, 0.72 for gooseberry, and 0.68 for highbush blueberry) agreed closely with those calculated for other crops. Values of 0.69 have been reported for pepper (De Swart et al., 2004), 0.64 for eggplant (Rivera et al., 2007), 0.63 for zucchini squash (Rouphael et al., 2006), 0.68 for sunflower (Rouphael et al., 2007), and 0.63 for broccoli (Stoppani et al., 2003). 

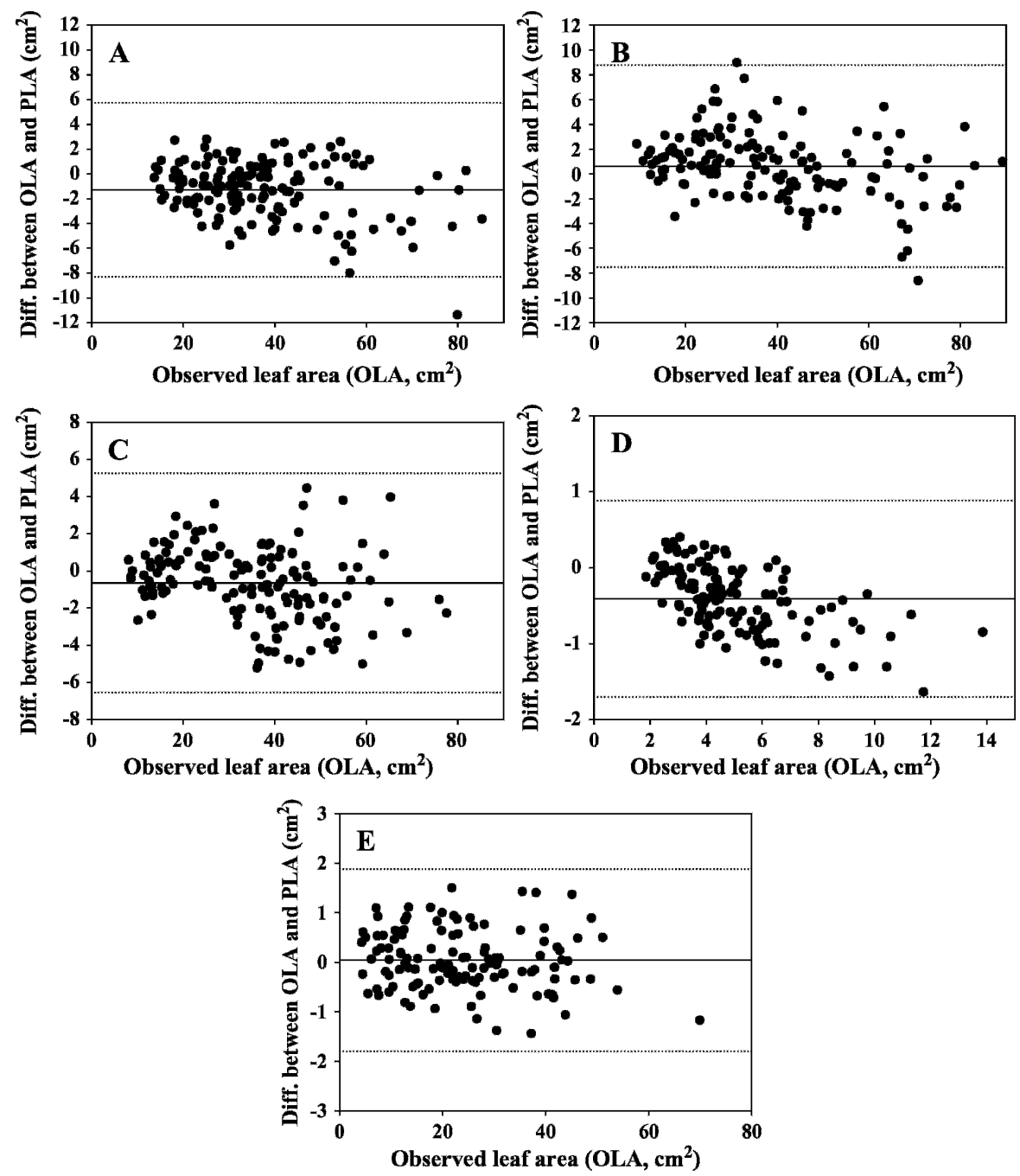

Fig. 2. The difference between predicted leaf areas (PLA) estimated by Model 3 from pooled data from 27 small fruit berry cultivars and observed leaf area (OLA) versus the observed leaf area of 'Autumn Bliss' (raspberry, A), 'Rovada' (redcurrant, B), 'Hull Thornless' (blackberry, C), 'Careless' (gooseberry, D), and 'Coville' (highbush blueberry, E) during 2007 (validation experiment). The solid line is the mean of the differences. The broken lines are the limits of agreement, calculated as $d \pm 3 \mathrm{sD}$, where $d$ is the mean of the differences and SD is the standard deviation of the differences. If the differences are normally distributed, $97 \%$ of the differences in a population will be lie between the limits of agreement.

Model validation. Parameter estimates and statistics obtained from SPSS outputs are presented for the LA estimation and validation models (Table 2 ). The regression coefficients for LW determined in the esti- mation models were very similar to that of the validation models for all small fruit berries and the $R^{2}$ values were similar for both models (Table 2 ), indicating the applicability of the proposed Model 3 to data beyond those on which the model is based (Neter et al., 1996). Moreover, a means of measuring the actual predictive capability of the models is to use them to predict each case in the validation data set and then to calculate the MSPR. If the MSPR is fairly close to the MSE based on the regression fit to the estimation data set, then the MSE for the selected regression model is not seriously biased and gives an appropriate indication of the predictive ability of the model. In the current study, the MSPR from the validation data set for raspberry leaf area did not differ greatly from the MSE of the estimation data set (Table 2). The same case was also observed for the redcurrant, blackberry, gooseberry, and highbush blueberry leaf area models (Table 2). This implies that the MSE based on the estimation data set is a reasonably valid indicator of the predictive ability of the estimation regression model (Neter et al., 1996).

Comparisons between OLA versus PLA using Model 3 for the validation set derived from 2007 experiment showed a close correlation $(r=0.99, P<0.0001)$, and the PLA values were very close to the OLA values, giving an underestimation of $1.6 \%, 1.5 \%$, $1.9 \%, 2.9 \%$, and $0.7 \%$ in the prediction for raspberry, redcurrant, blackberry, gooseberry, and highbush blueberry, respectively (Fig. 1). However, correlation is an inappropriate analysis to explain relationship between PLA and OLA, and a plot of the differences between PLA and OLA against OLA may be more informative (Bland and Altman, 1986; Marini, 2001). Plotting differences against OLA value also allows investigation of possible relationships between measurement error and the true values. Lack of agreement between estimation PLA and OLA can be evaluated by calculating the bias, estimated by the mean of the differences (d) and the SD of the differences. In Figure 2, a solid line represents the mean of the differences. If the differences are normally distributed, $97 \%$ of the differences will lie between $\mathrm{d} \pm 3 \mathrm{SD}$, which is the case in the current study, in which a few plots were out of these lines, whereas the rest of the plots were placed between lines.

Table 2. Statistics and parameter estimates from regression model for leaf area (LA, $\left.\mathrm{cm}^{2}\right)$ estimation. ${ }^{2}$

\begin{tabular}{|c|c|c|c|c|c|c|c|c|c|c|}
\hline \multirow{2}{*}{$\begin{array}{l}\text { Statistic or parameter } \\
\text { estimate }\end{array}$} & \multicolumn{2}{|c|}{ Raspberry } & \multicolumn{2}{|c|}{ Redcurrant } & \multicolumn{2}{|c|}{ Blackberry } & \multicolumn{2}{|c|}{ Gooseberry } & \multicolumn{2}{|c|}{ Highbush blueberry } \\
\hline & E.M. & V.M. & E.M. & V.M. & E.M. & V.M. & E.M. & V.M. & E.M. & V.M. \\
\hline Intercept & 0.027 & 0.522 & 1.719 & -0.217 & 0.904 & 0.627 & 0.577 & 0.536 & 0.545 & 0.410 \\
\hline SE of intercept & 0.186 & 0.467 & 0.187 & 0.472 & 0.176 & 0.380 & 0.088 & 0.069 & 0.127 & 0.118 \\
\hline $\begin{array}{l}\text { for length-width } \\
\text { SE of regression coefficient }\end{array}$ & 0.002 & $\begin{array}{l}0.701 \\
0.008\end{array}$ & $\begin{array}{l}0.089 \\
0.005\end{array}$ & 0.008 & 0.005 & 0.007 & 0.010 & 0.011 & 0.011 & 0.003 \\
\hline Prediction sum of squares & 4,677 & & 4,183 & & 2,755 & & 109 & & 47 & \\
\hline Error sum of squares & 4,633 & 738 & 4,139 & 954 & 2,731 & 562 & 108 & 16 & 46 & 48 \\
\hline Mean square error & 7.759 & 7.761 & 7.154 & 7.148 & 4.610 & 4.598 & 0.370 & 0.373 & 0.270 & 0.280 \\
\hline$P>\mathrm{F}$ & $<0.000$ & $<0.000$ & $<0.000$ & $<0.000$ & $<0.000$ & $<0.000$ & $<0.000$ & $<0.000$ & $<0.000$ & $<0.000$ \\
\hline $\begin{array}{l}\text { Coefficient of multiple } \\
\text { determination } R^{2}\end{array}$ & 0.982 & 0.979 & 0.980 & 0.981 & 0.975 & 0.985 & 0.974 & 0.968 & 0.986 & 0.998 \\
\hline
\end{tabular}

${ }^{\mathrm{z}}$ The estimation models (E.M.) were developed from 27 small fruit berry cultivars sampled in 2006. Validation models (V.M.) were developed from five small fruit berry cultivars sampled in 2007. 


\section{Conclusions}

To summarize, we can conclude that the length-width model can provide more accurate estimations of small fruit berries' LA across cultivars than those based on single length or width measurement. Because leaf width and midvein length are dimensions that can be easily measured in the field, greenhouse, and pod experiments, use of this model would enable researchers to make nondestructive measurements or repeated measurements on the same leaves. Such models can estimate accurately and in large quantities the LA of small fruit plants in many experimental comparisons without the use of any expensive instruments, e.g., a LA planimeter or digital camera with image measurement software.

\section{Literature Cited}

Beerling, D.J. and J.C. Fry. 1990. A comparison of the accuracy, variability and speed of five different methods for estimating leaf area. Ann. Bot. (Lond.) 65:483-488.

Bignami, C. and F. Rossini. 1996. Image analysis estimation of leaf area index and plant size of young hazelnut plants. J. Hort. Sci. 71:113-121.

Bland, J.M. and D.G. Altman. 1986. Statistical methods for assessing agreement between two methods of clinical measurements. Lancet i:307-310.

Bounous, G., G. Beccaro, M. Baudino, F.R. De Salvador, T. Eccher, R. Giordano, B. Mezzetti, and A. Pititto. 2004. Piccoli frutti. L'Informatore Agrario 24:71-77.

Cankaya, S., G.Y. Kayaalp, L. Sangun, Y. Tahtali, and M. Akar. 2006. A comparative study of estimation methods for parameters in multiple linear regression model. J. Appl. Anim. Res. 29:43-47.

Cho, Y.Y., S. Oh, M.M. Oh, and J.E. Son. 2007. Estimation of individual leaf area, fresh weight, and dry weight of hydroponically grown cucumbers (Cucumis sativus L.) using leaf length, width, and SPAD value. Sci. Hort. 111:330-334.
Cristofori, V., Y. Rouphael, E. Mendoza-De Gyves, and C. Bigniami. 2007. A simple model for estimating leaf area of hazelnut from linear measurements. Sci. Hort. 113:221-225.

Daughtry, C. 1990. Direct measurements of canopy structure. Remote Sens. Rev. 5:45-60.

Demirsoy, H., L. Demirsoy, and A. Ozturk. 2005. Improved model for the non-destructive estimation of strawberry leaf area. Fruits 60:6973.

Demirsoy, H., L. Demirsoy, S. Uzun, and B. Ersoy. 2004. Non-destructive leaf area estimation in peach. Eur. J. Hort. Sci. 69:144-146.

De Swart, E.A.M., R. Groenwold, H.J. Kanne, P. Stam, L.F.M. Marcelis, and R.E. Voorrips. 2004. Non-destructive estimation of leaf area for different plant ages and accessions of Capsicum annuum L. J. Hort. Sci. Biotechnol. 79:764-770.

Gill, J.L. 1986. Outliers, and influence in multiple regression. J. Anim. Breed. Genet. 103:161175.

Goudriaan, J. and H.H. Van Laar. 1994. Modeling potential crop growth processes. Kluwer Academic Publishers, Dordrecht, The Netherlands.

Marini, R.P. 2001. Estimating mean fruit weight and mean fruit value for apple trees: Comparison of two sampling methods with the true mean. J. Amer. Soc. Hort. Sci. 126:503-510.

Marquardt, D.W. 1970. Generalized inverse, ridge regression and biased linear estimation. Technometrics 12:591-612.

Mendoza-de Gyves, E., Y. Rouphael, V. Cristofori, and F. Rosana Mira. 2007. A non-destructive, simple and accurate model for estimating the individual leaf area of kiwi (Actinidia deliciosa). Fruits 62:171-176.

Miranda, C. and J.B. Royo. 2003a. A statistical model to estimate potential yields in peach before bloom. J. Amer. Soc. Hort. Sci. 128:297-301.

Miranda, C. and J.B. Royo. 2003b. Statistical model estimates potential yields in pear cultivars 'Blanquilla' and 'Conference' before bloom. J. Amer. Soc. Hort. Sci. 128:452-457.

Miranda, C. and J.B. Royo. 2004. Statistical model estimates potential yield in 'Golden Delicious' and 'Royal Gala' apples before bloom. J. Amer. Soc. Hort. Sci. 129:20-25.
Neter, J., M.H. Kutner, C.J. Nachtshein, and W. Wasserman. 1996. Applied linear regression models. 3rd Ed., Homewood, Ill., Irwin.

Nyakwende, E., C.J. Paull, and J.G. Atherton. 1997. Non-destructive determination of leaf area in tomato plants using image processing. J. Hort. Sci. 72:225-262.

Panta, G.R. and D.S. NeSmith. 1995. A model for estimating area of muskmelon leaves. HortScience 30:624-625.

Peksen, E. 2007. Non-destructive leaf area estimation model for faba bean (Vicia faba L.). Sci. Hort. 113:322-328.

Rivera, C.M., Y. Rouphael, M. Cardarelli, and G. Colla. 2007. A simple and accurate equation for estimating individual leaf area of eggplant from linear measurements. European J. Hort. Sci. 70:228-230.

Rouphael, Y., G. Colla, S. Fanasca, and F. Karam 2007. Leaf area estimation of sunflower leaves from simple linear measurements. Photosynthetica 45:306-308

Rouphael, Y., C.M. Rivera, M. Cardarelli, S. Fanasca, and G. Colla. 2006. Leaf area estimation from linear measurements in zucchini plants of different ages. J. Hort. Sci. Biotechnol. 81:238-241.

Salerno, A., C.M. Rivera, Y. Rouphael, G. Colla, M. Cardarelli, F. Pierandrei, E. Rea, and F. Saccardo. 2005. Leaf area estimation of radish from linear measurements. Adv. Hort. Sci. 19:213-215.

Schwarz, D. and H.P. Kläring. 2001. Allometry to estimate leaf area of tomato. J. Plant Nutr. 24:1291-1309.

Serdar, U. and H. Demirsoy. 2006. Non-destructive leaf area estimation in chestnut. Sci. Hort. 108:227-230.

Stoppani, M.I., R. Wolf, N. Francescangeli, and H.R. Martí. 2003. A nondestructive and rapid method for estimating leaf area of broccoli. Adv. Hort. Sci. 17:173-175.

Uzun, S. and H. Celik. 1999. Leaf area prediction models (Uzçelik-1) for different horticultural plants. Tr. J. Agr. For. 23:645-650.

Williams, L. and T.E. Martinson. 2003. Nondestructive leaf area estimation of 'Niagara' and 'DeChaunac' grapevines. Sci. Hort. 98:493498. 